\title{
The Use of a Mobile Application to Teach Concussion-Related Health Knowledge
}

\author{
Brinley Kantorski ${ }^{1,2}$, Danielle R. Commisso ${ }^{2}$, Camellia W. Sanford-Dolly ${ }^{3}$, and John A. Pollock ${ }^{1,2,4}$ \\ ${ }^{1}$ Department of Biological Sciences, Bayer School of Natural and Environmental Science, ${ }^{2}$ The Partnership in Education, and ${ }^{4}$ The Chronic Pain Research Consor- \\ tium, Duquesne University, Pittsburgh, Pennsylvania; and ${ }^{3}$ Rockman et al., San Francisco, California \\ Keywords: STEM Education, Health Literacy, Concussion, iOS/Android App, Interactive Reading, Serious Game, e-Learning, Traumatic Brain Injury \\ Publication Date: May 7, 2020
}

DOl: https://doi.org/10.15695/jstem/v3i1.05

\begin{abstract}
Sports-related concussions affect over 280,000 adolescents each year while the general public remains ill-informed about concussions, signs/symptoms, and treatments. Adolescents may be at an increased risk for experiencing adverse physiological and psychological effects from concussions, underscoring the critical need for effective concussion education strategies. While mobile apps are increasingly being used in education and healthcare settings, none were found to offer comprehensive concussion education capable of reaching diverse audiences. The interactive mobile app "Rebound: Beating Concussions" has the potential to be an effective teaching tool for school athletic programs and medical professionals to communicate important concussion-related information to student athletes, parents, and sports coaches. A mixed methods study was used to determine the app's ability to convey information about concussions to student athletes in grades 5 through 12, parents of student athletes, and sports coaches. Concussion knowledge and participant opinions were assessed via a pre/post model and administered before and after app use. Participants demonstrated knowledge gains in the identification of concussion symptoms, treatments, and misconceptions. Additionally, participants demonstrated positive opinions on the content of the app, its relevance to everyday life, and its potential as a teaching tool.
\end{abstract}

\section{INTRODUCTION}

Traumatic brain injury (TBI) is a widespread public health problem with 1.6 to 3.8 million sports/recreation-related concussions occurring each year (Daneshvar et al., 2011). Adolescents account for the majority of sports-related concussions (Halstead et al., 2018) with over 280,000 seeking care in emergency departments annually (Sarmiento et al., 2019). TBI can lead to emotional, physiologic, and cognitive effects in children (CDC Traumatic Brain Injury) who may be at an increased risk. Relative to adults, adolescents do not have fully developed axon myelination specifically in the temporal lobes. They also have thinner cranial bones, weaker neck muscles, and immature brain autoregulation (Buzzini and Guskiewicz, 2006; Sarmiento et al., 2019). Research indicates that children with sports-related concussions experience longer recovery times than adults (Elbin et al., 2016). Left untreated, concussions can have long-lasting effects. Thus, proper diagnosis and treatment is critical for recovery.

Research findings from a Harris Poll Report (2015) suggest that the general public is ill-informed about concus- sions, and their signs/symptoms and treatments. It is estimated that 9 in 10 American adults could not correctly define a concussion. Furthermore, $68 \%$ did not know that a concussion can occur without a direct hit to the head. Most (79\%) did not believe or were uncertain that a concussion can be cured and only $29 \%$ believe that concussions are treatable. Additionally, about 1 in 2 understood that it is not necessary to stay awake for 24 hours after getting a concussion, and less than half understood the importance of limiting physical activity and not participating in competitive activities until cleared (Harris Poll Report, 2015). It is also estimated that $50 \%$ to $70 \%$ of concussions go unreported or undetected, due in part to the 'culture of sports' and poor awareness of the signs and symptoms (Elbin et al., 2016). One study found that only $40 \%$ to $45 \%$ of high school athletes reported their sports-related concussion (Halstead et al., 2018). Clinical guidelines recommend that if an athlete is suspected of having a sports-related concussion, they should immediately be removed from play to decrease the risk of repeat injury, 
including the rare but potentially fatal condition of second impact syndrome. Yet, many athletes, parents and coaches fail to fully recognize the signs of concussion or acknowledge the dangers of playing with a concussion, compounded by athletes who choose not to report symptoms out of fear of being removed from participation, adding risk for prolonged recovery or worse (CDC Facts for Coaches; Delaney et al., 2015; Elbin et al., 2016; Wallace et al., 2017).

The Harris Poll Report (2015) highlighted the divide between misconceptions about concussions combined with competitive attitudes towards playing sports. About $25 \%$ of parents surveyed would not let their children participate in contact sports out of fear regarding concussions, while others did not understand the risks of continuing to play sports after sustaining a concussion. While $77 \%$ of the adults indicated that an athlete should not return to play after sustaining a concussion, $71 \%$ felt that too often, athletes are encouraged to keep playing right after injury. The level of confusion is profound and clearly there is a need to provide sound, evidence-based education about TBI, particularly sports-related concussions for adolescents. We believe that a narrative-based interactive app will be an engaging way to communicate important information to a diverse audience.

A review of literature suggests that mobile apps can be beneficial in educating and promoting healthy living. Apps are being used in traditional educational settings to enhance learning (e.g., science classroom) (Keeley et al., 2015; Teri et al., 2014) as well as in clinical practice, where they can aid patients and health professionals (Brown et al., 2015; Gielen et al., 2015; Lee et al., 2015; Real et al., 2019; Roy et al., 2017; Worthen-Chaudhari et al., 2017). The majority of concussion-related apps that exist are practical applications geared towards medical personnel focused on symptom recognition, diagnosis, and management (Davis et al., 2015; Lee et al., 2015). While there is certainly a need for digitized user-friendly concussion diagnostics, there is also a need to provide educational resources for school athletic trainers, coaches/teachers, students/parents, and medical professionals. Our approach is focused on the perspective that student athletes, parents, and trainers/coaches can benefit by developing an increased awareness and a better understanding of risks, symptoms, and treatment and recovery from sports-related concussions. This is achieved through BiblioTech ${ }^{\mathrm{TM}}$ "Rebound: Beating Concussions," a narrative-based app about sports-related concussions, that serves as a learning tool for students/student athletes, as well as parents and coaches.

BiblioTech" "Rebound: Beating Concussions" is a free iOS/Android app for smart phones and tablets. Assessment of the first app in the series, BiblioTech" "CityHacks: In Search of Sleep," showed it to be an effective tool in teaching both students and adults about the importance of sleep and the science behind it (Kantorski et al., 2019). Informed by that study, we applied the same platform and design to "Rebound: Beating Concussions." Geared towards 4th to 7th grade reading levels for students in late elementary school through early high school, we focused on concussion diagnosis, treatment, and recovery as depicted through a fictional narrative, reading-based format. Aspects of the story address fundamental principles about the biology of the brain and nervous system, as well as sports injury and safety.

The "Rebound: Beating Concussions" narrative features the fictional character of 9th-grader, Daniel Garcia, who is trying to help his twin sister, Isabel, rejoin her basketball team after she has suffered a concussion from an impact on the court. Daniel must gather information about concussions and share that information with his family and the basketball coach, so his sister can safely return to the team. The app contains a highly interactive "choose-your-own-adventure" format; the user makes choices that affect the storyline, such as deciding whether to visit a public library, a bike shop, or a beach to look for information about concussions (Figure 1). Throughout the story, users must collect information about concussions and store it in a digital notebook via a "drag and drop" mechanism (Figure 2). Users are then asked to apply their notes in two assessments; first, in order to move on to the second half of the story, and second, in order to convince Isabel's basketball coach that because she has fully recovered from her concussion, it is safe for her to return to play. Convincing the coach is a challenge because he believes commonly-held myths about concussions. If Daniel successfully dispels the myths with science-backed facts, then Isabel can play.

The story is supplemented with mini-games, quizzes, diagrams and simulations, as well as video Q\&A with an athletic trainer. The interactive elements are designed to support the content of the story. For example, one interactive is a simulation of the diagnostic tool, ImPACT ${ }^{\circledR}$, a

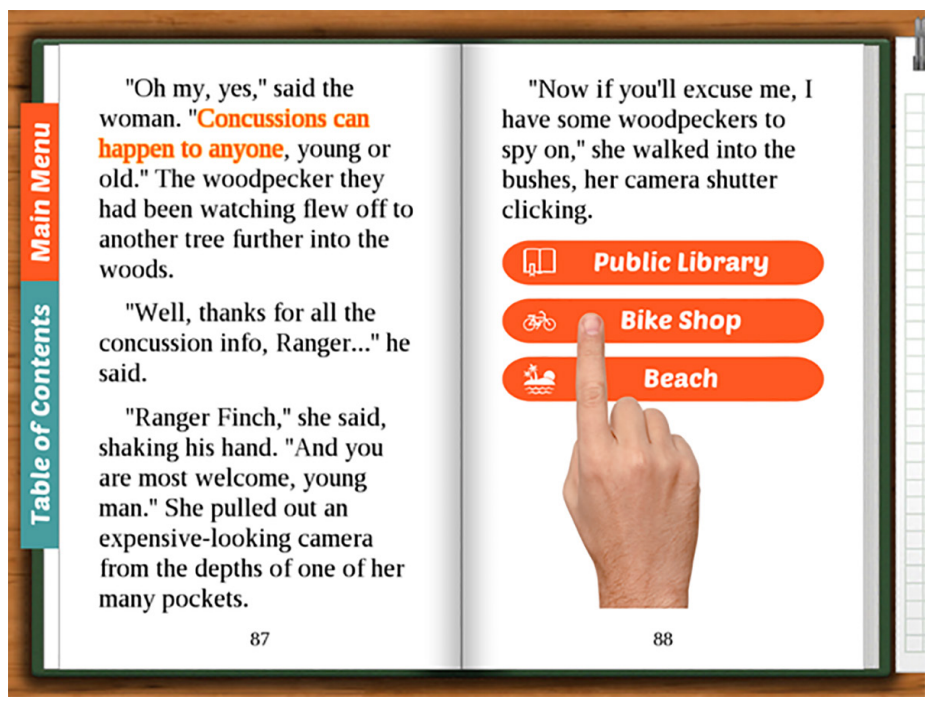

Figure 1. Users select which locations Daniel visits throughout the story. 


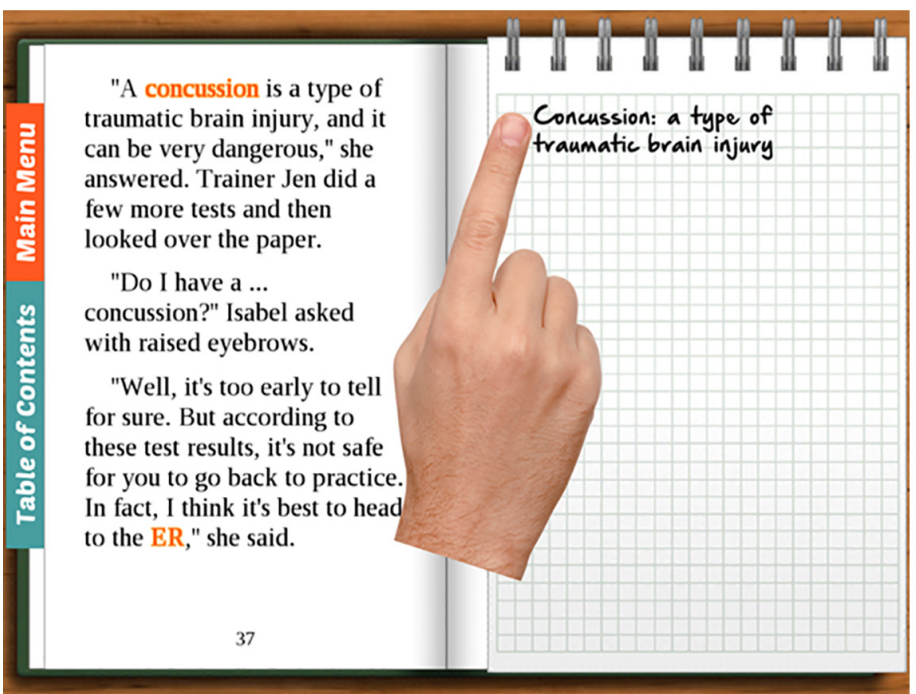

Figure 2. Users drag and drop information and vocabulary words into a digital notebook while reading. Some of these notes are key to answering questions later in the narrative; allowing the user to progress. Incorrect answers re-direct the user to further opportunities to discover the correct information.

computer-based neurocognitive test that scores verbal and visual memory, processing speed, and reaction time (Elbin et al., 2016). Other interactive graphics highlight eye-tracking deficits that can occur as a result of a concussion (Voelker, 2019; Zahid et al., 2018). Furthermore, users can adjust the reading level of the text, using the Adaptive Reader ${ }^{\mathrm{TM}}$ feature (Figure 3), increasing or decreasing the reading level depending on the users' needs or interests (Kantorski et al., 2019). With the Adaptive Reader ${ }^{\mathrm{TM}}$, the key vocabulary as well as sentence structure is altered without changing the narrative or the learning goals. In this way, the overall utility of the app as a story is broadened to be inclusive for students with differing reading proficiency, now able to access the story and learn equally.

The storyline and content for "Rebound" was developed in consultation with neuroscientists, medical doctors, a physical therapist, an athletic trainer, and adolescent concussion patients. The content was advised and reviewed by experts from the UPMC Sports Medicine Concussion Program, who have contributed to a new understanding of concussions and have also developed effective therapies (Collins et al., 2014). What was previously considered to be one thing, concussion is now recognized as a range of distinct challenges: cognitive/fatigue, vestibular, ocular, post-traumatic migraine, cervical, and anxiety/mood (Broglio et al., 2015). "Rebound: Beating Concussions" incorporates concepts of these varied clinical manifestations into the narrative, while providing insight into the unique therapies they require. The app also integrates diagnostic tools into the storyline (Figure 4) (Lee et al., 2015), emphasizes the importance of involving medical professionals in every step of concussion diagnosis, treatment, and return to physical activity, and adheres

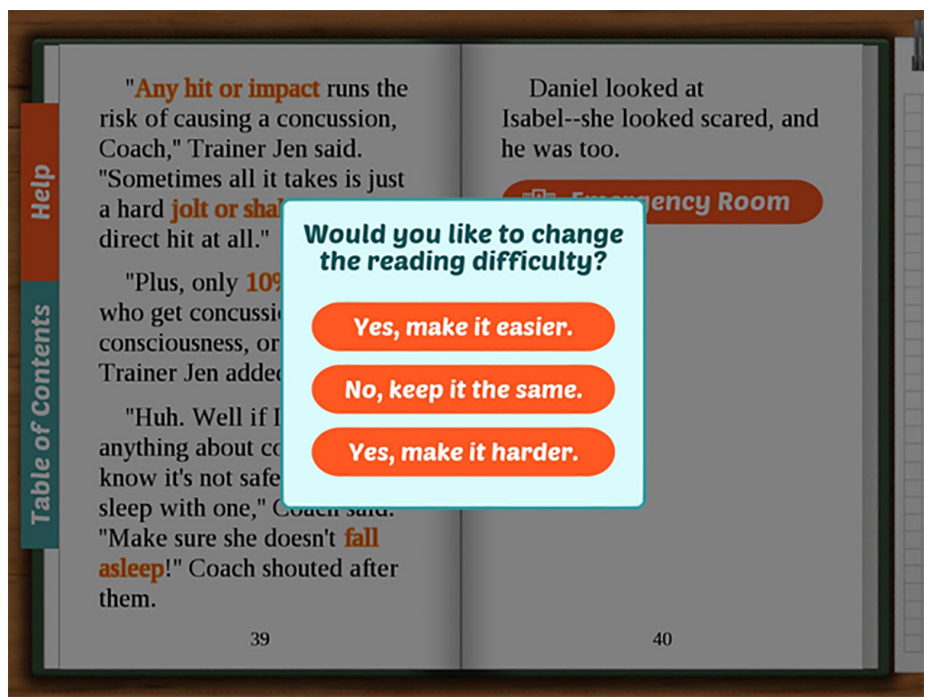

Figure 3. A screenshot from "Rebound" showing the prompt to scale the reading level up, down, or keep it the same.

to recommendations put forth by the CDC Pediatric Mild TBI Guideline (Lumba-Brown et al., 2018). Here, we show that using the app significantly increases knowledge and understanding of concussion symptoms; increases knowledge and understanding of what a concussion is and how it can be treated; and dispels commonly-held misconceptions about concussions. We discuss findings that demonstrate learning outcomes in all three areas as well as likeability, relevance, and potential for future implementation of the app in educational and pediatric health care settings.

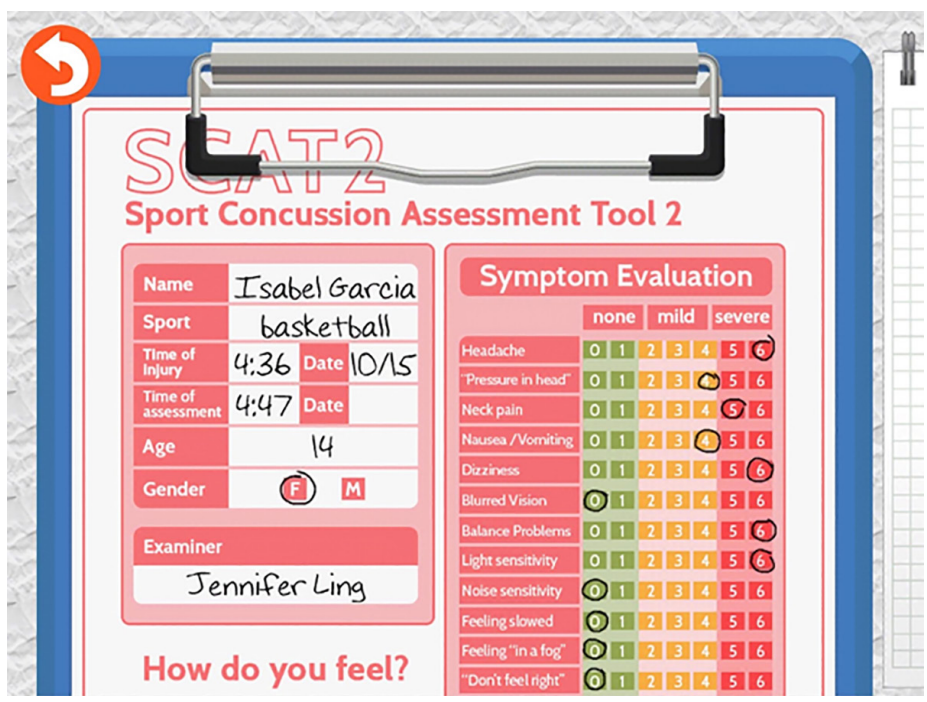

Figure 4. A still of the SCAT2 infographic that appears in the story.

\section{METHODS}

A mixed methods approach targeted three different populations: student athletes, parents of student athletes, and coaches of student athletes. In the study, both quantitative data and qualitative data were collected. Quantitative data 
was generated from participants' responses to content knowledge-based questions related to concussions, as well as their responses to opinion-based questions related to the function, content, and usability of the app. Qualitative data was generated from participant interviews conducted via phone. This combination of data helped to provide a well-rounded and comprehensive understanding of the app's impact on participants' knowledge of concussion-related content, as well as their thoughts and opinions of the app itself.

Participant Demographics. Participants included student athletes in grades 5-12, their parents, and coaches of middle and high school sports teams. In total, 25 individuals participated: 14 student athletes, seven parents, and four coaches. Table 1 details participant demographic makeup. Of the parents who participated in the study, four parents had one child who also participated in the study, while three parents had multiple children who participated in the study. Each coach represented different sports: one coached basketball and baseball, one coached soccer, one coached kendo, and one coached gymnastics. Study participants were recruited via email, Facebook social media posts, and paper fliers distributed at youth sporting events and local gyms in California's Central Valley, as well as the Greater Pittsburgh metropolitan area.

Table 1. Participants by Gender and Ethnicity.

\begin{tabular}{|l|c|c|c|c|}
\hline \multicolumn{1}{|c|}{ Gender } & Coaches & $\begin{array}{c}\text { Student } \\
\text { Athletes }\end{array}$ & Parents & $\begin{array}{c}\text { All } \\
\text { Participants }\end{array}$ \\
& & & \\
\hline Male & 3 & 8 & 7 & 18 \\
\hline Female Ethnicity & 1 & 6 & 0 & 7 \\
\hline White/Caucasian & 3 & 12 & 6 & 21 \\
\hline African American & 0 & 2 & 1 & 3 \\
\hline Asian & 1 & 0 & 0 & 1 \\
\hline
\end{tabular}

Study Activities. The study instrumentation can be found in Appendix A. Briefly, after the nature of the study was explained to interested participants they were asked to sign a consent form indicating their willingness to participate and then took an online pre-test of demographic questions, true/false statements related to concussion misconceptions, questions on concussion-related terms and definitions, and open-ended questions regarding the symptoms and treatment of a concussion. Then they were instructed to download the "Rebound: Beating Concussions" app, use the app, and fill out a usage log. Most study participants (21 out of 25 ) filled out at least some portion of the usage log. Following that they were asked to fill out an online post-test. All study participants $(\mathrm{N}=25)$ completed the post-test and each received a $\$ 30$ Amazon gift card as compensation for their time and feedback. A subset of participants (three coaches, three parents, and three student-athletes) were invited to participate in short telephone interviews to gather more in-depth information about the use and impact of the app (all agreed). Interviews lasted between 15-30 minutes. Interviewees were given an additional $\$ 10$ Amazon gift card for their participation.

Statistical Analysis. The resulting data from the pre- and post-test instruments were analyzed via Excel and SPSS software. Data comparing pre-post mean differences from participants were analyzed via repeated measures t-tests. Some open-ended survey responses were coded for themes and then compared quantitatively, while other survey and interview responses were organized by key takeaways.

\section{RESULTS}

We find that "Rebound: Beating Concussions" is an effective learning tool, providing 1) increased knowledge and understanding of concussion symptoms, 2) increased knowledge and understanding of what a concussion is and how it can be treated, and 3) dispelling commonly-held misconceptions about concussions. We also highlight key qualitative findings concerning likeability of the app, its relevance to the participants' lives, and its potential applications.

\section{Quantitative Assessment.}

Understanding Concussion Symptoms. After using the app, the data shows that the study participants were able to list significantly more concussion symptoms than they had prior to using the app, increasing the average number of identified symptoms from 2 to 3 on the pre-test, to 3 to 4 on the post-test (Figure 5). Study participants were significantly more likely to identify symptoms such as nausea, being off balance, and changes in mood after using the app. On the pre-test, $25 \%$ of participants were able to identify nausea as a possible concussion symptom, compared to $50 \%$ of participants who were able to identify it on the post-test. No one identified being off balance as a possible concussion symptom on the pre-test, while $17 \%$ could on the post-test. Increases were also seen in the number of participants who were able to identify other symptoms, however these increases were not significant. This may be due to the fact that these symptoms are more commonly known and therefore would be familiar to the participants before using the app. Interestingly, symptoms categorized as "Other," including lack of appetite, ringing in ears, and difficulty sleeping, were identified significantly less after using the app (Figure 5).

Understanding Concussion Treatments. In addition to increased ability to identify possible concussion symptoms 
Percentage of Study Participants Who Identified the Symptom Before and After Using the App

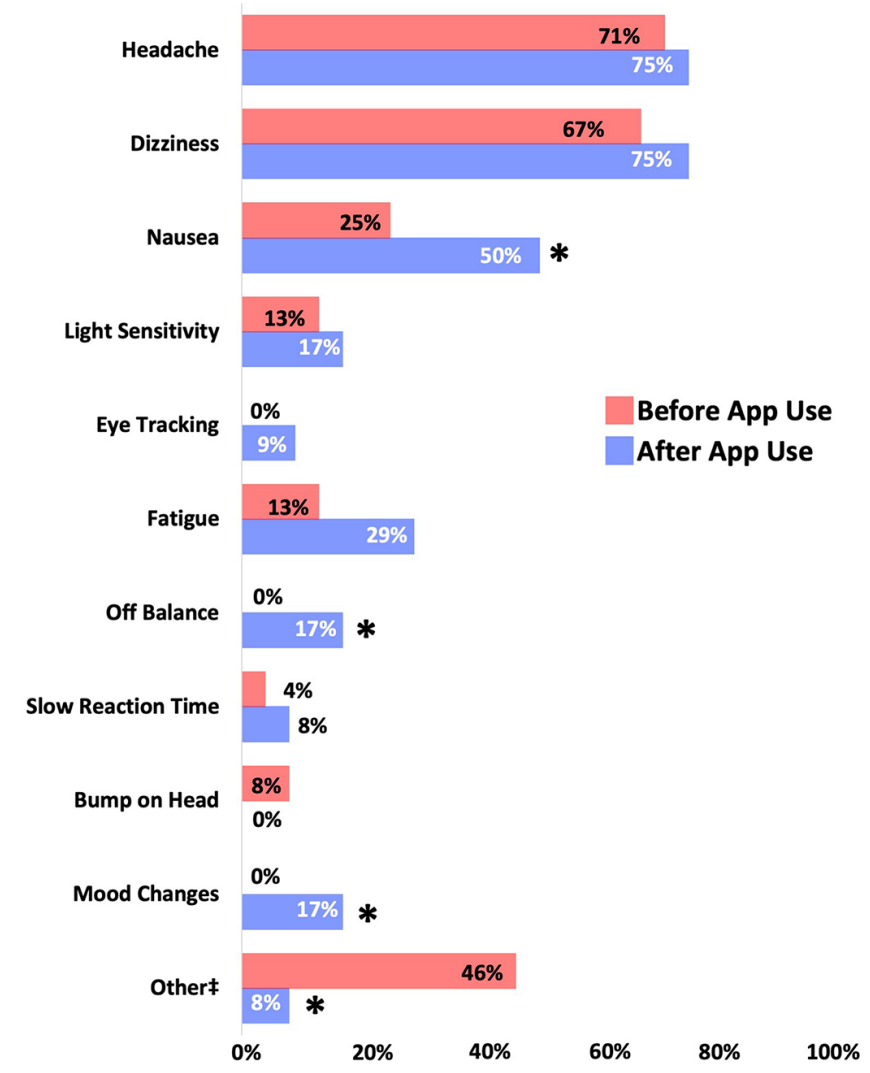

Figure 5. Percentage of participants who identified possible concussion symptoms on the pre-test and post-test. +'Other" includes lack of appetite, ringing in ears, and difficulty sleeping. *Indicates a significant difference between pre- and post-testing.

after using the app, participants were also able to list significantly more concussion treatments (Figure 6). On the pre-test, on average, participants were able to identify only one possible concussion treatment, while on the post-test, participants were able to identify two possible treatments. Furthermore, before using the app, only $13 \%$ of study participants were able to identify brain rest as a possible concussion treatment, while $42 \%$ of study participants were able to identify it after using the app. One coach mentioned in a phone interview that a key learning point for him was learning "if you suffer a concussion, that it's best not to overwork the brain and let it rest..." Few (8\%) identified physical therapy as a possible concussion treatment before using the app, which increased to $33 \%$ of participants afterwards. No one identified nutrition as a possible concussion treatment on the pre-test, while $17 \%$ of participants mentioned it on the post-test. A significant decrease was seen in the number of participants who identified medication as a possible concussion treatment from $21 \%$ on the pre-test to $0 \%$ on the post-test. This decrease may have been caused by the intentional limited focus on medication as a treatment in the narrative of the app.

Concussion Misconceptions. Study participants also

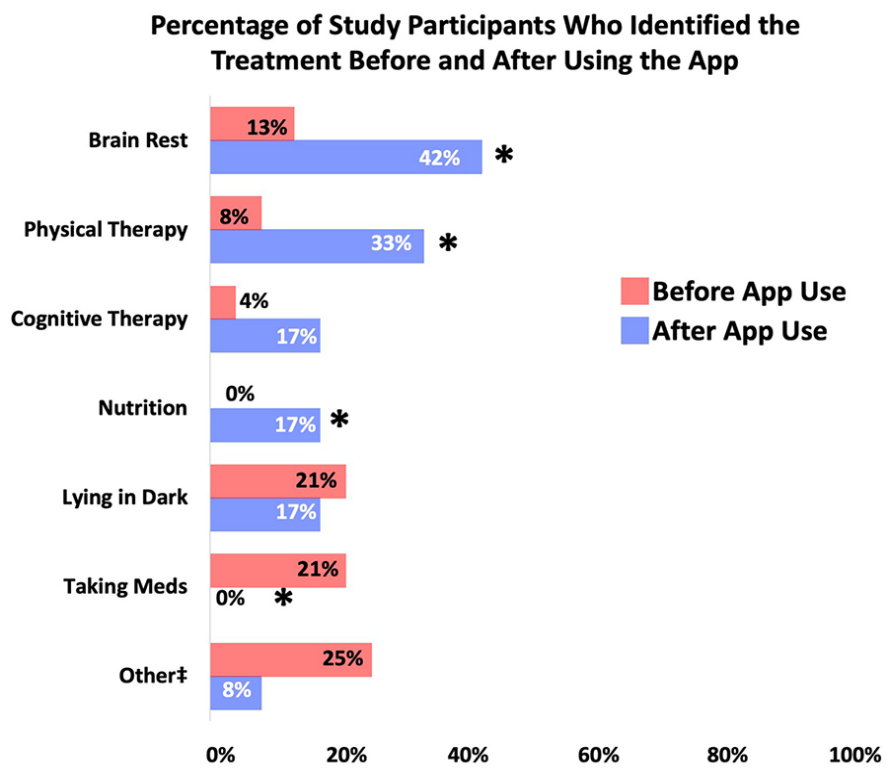

Figure 6. Percentage of participants who identified possible concussion treatments on the pre-test and post-test. *"Other" category includes the participant-generated responses of "getting medical attention," "going to the doctor," "getting plenty of fluids," "quiet interactions," and "I don't know." *Indicates a significant difference between pre- and post-testing.

demonstrated an increased ability to recognize concussion myths and misconceptions after using the app (Figure 7). Significant differences between pre- and post-test scores were observed in reference to participants' vetting of five concussion statements. For example, the statement, "You can get a concussion without a direct hit to the head" was correctly identified as being true by $54 \%$ on the pre-test, increasing to $83 \%$. We also found that $42 \%$ of participants correctly identified the statement, "It's not safe to go to sleep after you get a concussion" as being false on the pre-test, compared with $83 \%$ after. The statement, "There is no machine that can detect a concussion" was correctly identified as being true by only $25 \%$ on the pre-test, while $71 \%$ correctly identified the statement as true after reading the story. Regarding the statement, "A person with a concussion should always stay in a quiet, dark room to recover" as being false, $46 \%$ were correct before reading the app, which increased to $88 \%$ afterwards. One parent stated in a phone interview, "The myths that were dispelled in the app were things that I grew up knowing about...concussions." For virtually all concepts, participants exhibited an improved understanding, though some were not significant. However, no difference was observed between pre-test and post-test for the statement, "Concussions only happen to people playing sports" where $96 \%$ of study participants were able to correctly identify this statement as being false. The three non-significant differences are likely due to participants' already high levels of understanding around the three statements (i.e., there was less room for improvement). Most notably, before using the app, study participants were able to correctly identify the ve- 


\section{Percentage of Study Participants Who Correctly Identified the Veracity of the Concussion Statement Before and After Using the App}

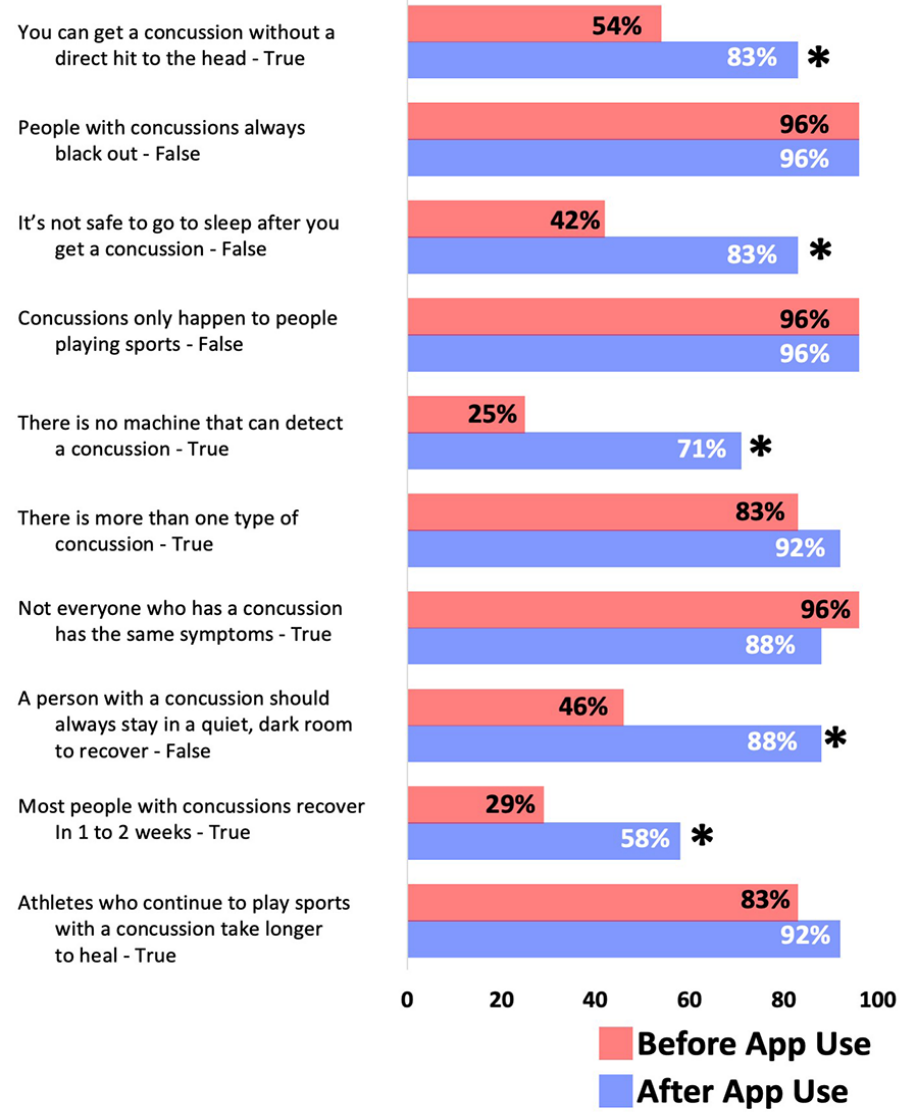

Figure 7. Percentage of participants who correctly identified statements about concussions as being true or false on the pre-test and post-test. *Indicates a significant difference between pre- and post-testing.

racity of 7 out of 10 concussion statements. After using the app, study participants were able to correctly identify the veracity of 9 out of 10 concussion statements, a significant increase, $\mathrm{t}(23)=-3.582, \mathrm{p}=.002$.

One coach stated in a phone interview:

\section{I liked how they used the coach to introduce the myths associated with concussions and have the main char- acter overcome that... Before using the app, I wouldn't have known any of this either, so I probably would have been in a similar spot. I thought that was a nice touch.}

Quantitative data gathered from the pre- and post-tests clearly demonstrates that "Rebound" is a tool that can be used to impart important concussion-related information to student athletes, parents, and coaches. After using the app, study participants were able to accurately identify more concussion symptoms and potential concussion treatments, and verify the accuracy of concussion-related statements.
Qualitative Assessment. In addition to assessing learning, we collected qualitative data on the likeability of "Rebound," including users' interest in the app's content and storyline; enjoyment and perceived utility of features; and attitudes regarding the perceived relevance of the app to participants' lives and its application in a school setting. Reception was largely positive, with some notable variations between student athletes, parents, and coaches. These measures are important for establishing the likelihood that people will actually use the app.

Likeability of the App, Storyline, and Content. On the post-test, participants were asked a series of questions to assess their feelings and attitudes towards the app including storyline, content, and overall likeability. Using a Likert scale from 1 to 4 , with 1 being the least favorable and 4 being the most favorable (1="No, not at all!", $2=$ "No, not really", 3= "Yes, somewhat", 4= "Yes, totally!"), the responses are displayed in Figure 8 and depict the average ratings of all participants for each category, as well as a breakdown of individual ratings for coaches, student athletes, and parents.

When asked, "Did you like the app overall?" the majority of participants $(76 \%, \mathrm{~N}=25)$ answered favorably, with coaches rating the app most highly (Figure 8). One parent shared, "It's interesting, the concept of going about reading a story...It was different than just playing games. It was a reading app, but a learning app." Most of the participants indicated that the narrative format itself was interesting (92\%, $\mathrm{N}=25$ ) with one coach commenting, "At first I was expecting a lecture, but was more easily looped into a story, where you discover along with the protagonist all of the information about concussions."

Feedback from phone interviews conducted with participants speaks to the likeability of the story's characters. One student athlete stated, "Daniel was very kind and very curious about his sister's concussion." A parent commented, "It was a good relationship between the parents and the kids. The storyline was cute in terms of the brother trying to help the sister learn more, trying to be a good problem solver." In general, participants felt that the familial relationships in the story were warm and relatable. Several participants appreciated the role of the female athlete in the story. Similarly, most participants $(92 \%)$ thought that the information provided in the app about concussions was interesting, with coaches expressing the highest level of interest (Figure 8). Overall, participants appreciated that the information was factual and straightforward. One parent commented, "The narrative was nice and engaging. The information was repeated in a helpful way, and the content was presented well with authority/credibility."

Activities and Features. A key feature that this study explored was the Adaptive Reader ${ }^{\mathrm{TM}}$, which allowed users to choose between three different text levels. All app users begin at the medium level, and are regularly prompted, through 
Participants' Average Ratings of the app's Likeability, Storyline, and Content

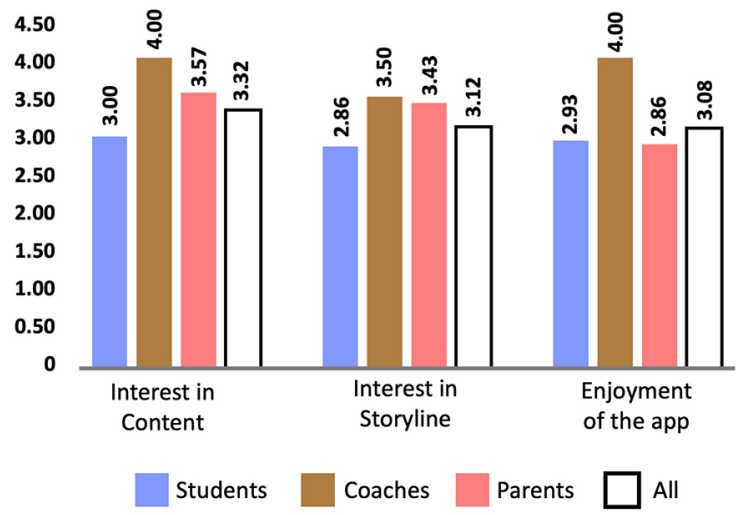

Figure 8. Interest in and enjoyment of the app. Participants' average ratings of the app's content, storyline, and likeability. Likert scale (1-4 rating).

a pop-up box, to make the text more challenging or easier to read if they wish (Figure 3). When asked, most participants $(80 \%)$ felt that the reading level of the app had been "just right" for them, while the remaining participants thought that the reading level had either been too easy $(16 \%)$ or too hard (4\%). Less than half of the study participants (44\%) adjusted the reading level while using the app. Participants who adjusted the reading level $(\mathrm{N}=11)$ tended to do so in order to make the story more challenging to read. Regardless of whether they had done so, many participants (68\%) thought that the ability to adjust the reading level in the app was a useful feature to include (Appendix B).

Relevance and Use as an Educational Tool. The app was viewed as relevant to the lives of participants (84\%), especially to coaches, and would be useful as a teaching tool in a school setting (Figure 9). One coach commented:

I'm actually going to a hockey game tonight with me playing. I feel like I'm going to be more aware if someone gets hit...It helped me realize that there's more to look for than what I thought previously.

In phone interviews, one parent commented, "I liked the concept. I think it's a cool idea for kids to have an interactive way to learn and apply some of the concussion ideas and concepts. I don't think [concussion] is something we would normally just pick up and research." Another parent shared, "Ironically, while I was using it, I met my friend for lunch who had to take her son to the doctor because she thought he had a concussion, and I was like, 'Wait! I know things!' So, I used it right away, the content." A student athlete offered a different perspective stating, "[I liked] learning about concussions and how to treat them to get back to whatever you were doing before." These sentiments reflect the app's relevance to users' lives.

Participants also saw the app's inherent educational val- ue. One parent elaborated, "I could see this being a great teaching tool to use. Before [my daughter] signed up for sports for school, the parents and her had to sign a one-sheet on concussions...I can see this being much better at helping kids understand what a concussion is, what the treatment is, and what you should do." Interestingly, coaches were more likely to want to use the app in school than parents or student-athletes (Figure 9). In particular, coaches thought that the app was important to share with their students, in order to help students be better able to articulate their symptoms, if they suspect that they have a concussion. In a phone interview, one coach emphasized, "How important it is for

\section{Relevance of App to Participants' Lives and Desire to Use the App in School}

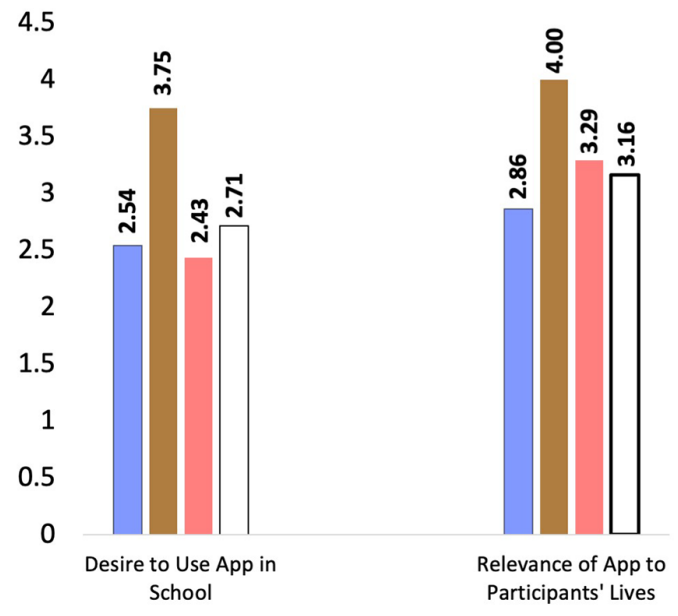

Students $\square$ Coaches $\square$ Parents $\square$ All

Figure 9. Desire to use the app in school and relevance of the app to participants' lives. Likert scale (1-4 rating).

athletes to understand symptoms of a concussion so as to communicate with coaches and doctors."

\section{DISCUSSION}

The study findings suggest that "Rebound: Beating Concussions" could be employed as a useful tool to engage adolescents and adults in learning about concussions and brain health. Specifically, student athletes, their parents and coaches stand to benefit from using the app by gaining an increased ability to identify symptoms, a greater understanding of concussion treatments, and an appreciation of common concussion misconceptions. The study also suggests that the interactive narrative-based approach employed in the app was effective at providing a powerful learning opportunity about concussions, and more broadly, science and health-literacy. While we achieve statistical significance in several categories of assessment, the size of the survey pool is a limitation to the study. Although beyond the scope of this particular study, assessment of broader demographics 
could be beneficial, including usage of the app in a structured classroom setting. Nonetheless, one strength of appbased educational approaches is the ability for self-guided learning. Keeley et al. (2015, p191) note that, "Apps provide students the freedom of mobile learning through handheld devices to learn at any time and any pace." The Adaptive Reader ${ }^{\mathrm{TM}}$ feature, which the majority of participants found to be a worthwhile addition (Appendix B), further enables users to tailor "Rebound" to fit users' personal needs. In this way, all users receive the same narrative and learning goals, while being allowed to read at their own level.

Researchers have proposed that effective concussion education strategies aimed at youth should be carried out through a multifaceted orchestrated approach involving multiple stakeholders (Patel et al., 2017). In this light, we identify stakeholders as athletic trainers, coaches, teachers, parents, student athletes, and pediatricians. Bolstered by positive reception of the use of "Rebound" in a school setting, we foresee implementation in school athletic programs guided by coaches, athletic trainers, or teachers. At the same time, pediatricians could implement the app through encouraging its use among their patients and in their communities. As outlined in a clinical report by the American Academy of Pediatrics (Logan and Cuff, 2019), participation in organized sports is shown to offer a wealth of benefits to children and adolescents, such as increased motor skill development, academic performance, and social interaction. However, drawbacks such as burnout and injury sustained from organized sports are risk factors that can stem from the influence of parents and coaches. The report suggests that pediatricians can help to mitigate these risks by educating and promoting healthy and safe organized sports programs. For example, they may help parents determine whether or not their child is developmentally ready to engage in a specific sport. Likewise, in encouraging the use of "Rebound," pediatricians could help to educate patients and families at annual physicals by encouraging use of the app, so that everyone is more informed about sports-related concussions and concussion symptoms, diagnosis, treatment, and common misconceptions prior to play.

In conclusion, we find that using "Rebound: Beating Concussions" increases knowledge and understanding about concussions among student athletes, parents, and coaches. Information was presented through a self-guided, interactive narrative that incorporated the latest concussion research, while also teaching fundamental principles of biology of the brain and nervous system. The study indicates that the "Rebound" app can effectively engage diverse audiences and provide critically needed concussion-related education, demonstrating increases in three key areas: 1) knowledge and understanding of concussion symptoms, 2) knowledge and understanding of concussion treatment, and 3) clarification of commonly-held misconceptions. Positive perception of the app's story, content and overall likeability, as well as its perceived relevance, supports the application of "Rebound" by school athletic programs as well as pediatricians.

Looking to the future, we hope to develop and launch a comparative study investigating the effectiveness of "Rebound" as a teaching tool in both classroom and in athletic program settings. While the use of educational games and apps have demonstrated themselves as effective tools for learning, additional research is needed to determine if products like "Rebound" are more or less effective than more traditional or commonly used teaching tools and methodologies (Annetta, 2009; Brom, 2011; Wilson, 2018). It may also be that an app like "Rebound" may simply offer an educator a new tool for student engagement, no better or worse than other teaching techniques; additional research is needed. A comparative study would also provide insights into whether or not "Rebound" could replace or supplement existing concussion education in both traditional science or health courses, athletic training programs, or even pediatric patient resources. Results from this and future studies could further inform the app's development with data providing insights for customization options in different use-case scenarios.

\section{ASSOCIATED CONTENT}

Supplemental material mentioned in this manuscript can be found uploaded to the same webpage as this the manuscript. Additional information about "Rebound: Beating Concussions" can be found at: https:/www.thepartnershipineducation.com/resources/bibliotech-tm-rebound-beating-concussions.

\section{AUTHOR INFORMATION Corresponding Author}

John A. Pollock, Department of Biological Sciences, Bayer School of Natural and Environmental Science, Duquesne University, 600 Forbes Ave., Pittsburgh, PA 15282. (412) 855-4043.pollock@duq.edu

\section{Author Contributions}

The manuscript was written through contributions of all authors. All authors have given approval to the final version of the manuscript.

\section{ACKNOWLEDGMENTS}

The authors extend their gratitude to the following: Rockman et al., Duquesne University, Simcoach Games, Drs. Micky Collins and Anthony Kontos (UPMC Sports Medicine Concussion Program), and Lauren Fingeret, Ph.D. We also want to thank the study participants for their time and thoughtful feedback on "Rebound: Beating Concussions". 


\section{FUNDING SOURCES}

All phases of this study were supported by a National Institutes of Health, National Institute of General Medical Sciences (NIGMS) Science Education Partnership Awards, R25 GM129180 (formerly R25 OD016516) and R25 GM132910. Additional support is from the Henry L. Hillman Foundation. The content is solely the responsibility of the authors and does not necessarily represent the official views of the National Institutes of Health.

\section{ABBREVIATIONS}

NIGMS: National Institute of General Medical Sciences; TBI: Traumatic Brain Injury.

\section{REFERENCES}

Annetta, L. A., Minogue, J., Holmes, S. Y., and Cheng, M.-T. (2009). Investigating the impact of video games on high school students' engagement and learning about genetics. Computers and Education, 53(1), 74-85. doi: 10.1016/j. compedu.2008.12.020.

Broglio, S. P., Collins, M. W., Williams, R. M., Mucha, A., and Kontos, A. P. (2015). Current and emerging rehabilitation for concussion: a review of the evidence. Clinical Sports Medicine, 34(2), 213-31. doi:10.1016/j.csm.2014.12.005.

Brom, C., Preuss, M., and Klement, D. (2011). Are educational computer micro-games engaging and effective for knowledge acquisition at high-schools? A quasi-experimental study. Computers and Education, 57(3), 1971-1988. doi: 10.1016/j.compedu.2011.04.007.

Brown, C. D., Keeley, K., and Pottieger, K. (2015). The use of apps in athletic training, Part I: Applications for sideline management. Human Kinetics -- International Journal of Athletic Therapy and Training, 20(3), 13-19. doi:10.1123/ ijatt.2014-0026.

Buzzini, S. R., and Guskiewicz, K. M. (2006). Sport-related concussion in the young athlete. Current Opinion in Pediatrics, 18(4), 376-382. doi: 10.1097/01.mop.0000236385.26284. ec.

CDC Facts for Coaches. A fact sheet for youth sports coaches. Centers for Disease Control and Prevention Web site. Retrieved from https://www.cdc.gov/headsup/pdfs/ youthsports/coaches_engl.pdf on February 8, 2020.

CDC Traumatic Brain Injury. Basic information about traumatic brain injury. Centers for Disease Control and Prevention Web site. Retrieved from https://www.cdc.gov/traumaticbraininjury/basics.html on February 9, 2020.

Collins, M. W., Kontos, A. P., Reynolds, E., Murawski, C. D., and $\mathrm{Fu}$, F. H. (2014). A comprehensive, targeted approach to the clinical care of athletes following sport-related concussion. Knee Surgery, Sports Traumatology, Arthroscopy, 22, 235-246. doi:10.1007/s00167-013-2791-6.
Daneshvar, D. H., Nowinski, C. J., McKee, A. C., and Cantu, R. C. (2011). The epidemiology of sport-related concussion. Clinical Sports Medicine, 30,1-17. doi:10.1016/j. csm.2010.08.006.

Davis, G. A., Thurairatnam, S., Feleggakis, P., Anderson, V., Bressan, S., and Babl, F. E. (2015). HeadCheck: A concussion app. Journal of Paediatrics and Child Health, 51, 830-831. doi:10.1111/jpc.12879.

Delaney, J. S., Lamfookon, C., Bloom, G. A., Al-Kashmiri, A., and Correa, J. A. (2015). Why university athletes choose not to reveal their concussion symptoms during a practice or game. Clinical Journal of Sport Medicine, 25(2),113-125. doi:10.1097/jsm.0000000000000112.

Elbin, R. J., Sufrinko, A., Schatz, P., French, J., Henry, L., Burkhart, S., Collins, M. W., and Kontos, A. P. (2016). Removal from play after concussion and recovery time. Pediatrics. 138(3), e20160910. doi:10.1542/peds.2016-0910.

Gielen, A. C., McDonald, E. M., Omaki, E., Shields, W., Case, J., and Aitken, M. A. (2015). A smartphone app to communicate child passenger safety: an application of theory to practice. Health Education Research, 30(5), 683-692. doi:10.1093/her/cyv035.

Halstead, M. E, Walter, K. D., and Moffatt, K. (2018). Sport-related concussion in children and adolescents. Pediatrics, 142, 6. doi:10.1542/peds.2018-3074.

Harris Poll (2015). How knowledgeable are Americans about concussions? Harris Poll Report, University of Pittsburgh Medical Center. Retrieved from http://rethinkconcussions. upmc.com/wp-content/uploads/2015/09/harris-poll-report.pdf on February 8, 2020.

Kantorski, B., Sanford-Dolly, C. W., Commisso, D. R., and Pollock, J. A. (2019). Backward design as a mobile application development strategy. Education Technology Research and Development, 67(3), 711-731. doi:10.1007/ s11423-019-09662-7.

Keeley, K., Potteiger, K., and Brown, C. D. (2015). Athletic training education: there's an app for that. Athletic Trainer Education, J. 10(2),190-199. doi:10.4085/1002190.

Lee, H., Sullivan, S. J., Schneiders, A. G. Ahmed, O. H., Balasundaram, A. P., Williams, D., Meeuwisse, W. H., and McCrory, P. (2015). Smartphone and tablet apps for concussion road warriors (team clinicians): a systematic review for practical users. British Journal of Sports Medicine, 49, 499-505. doi:10.1136/bjsports-2013-092930.

Logan, K., and Cuff, S. (2019). Organized sports for children, preadolescents, and adolescents. Pediatrics, 143, 6 . doi:10.1542/peds.2019-0997.

Lumba-Brown, A., Yeates, K.O., Sarmiento, K., ... and Timmons, S.D. (2018). Centers for Disease Control and Prevention Guideline on the diagnosis and management of mild traumatic brain injury among children. JAMA Pediatrics, 172, 11. doi:10.1001/jamapediatrics.2018.2853. 
Patel, D. R., Fidrocki, D., and Parachuri, V. (2017). Sport-related concussions in adolescent athletes: a critical public health problem for which prevention remains an elusive goal. Translational Pediatrics, 6(3), 114-120. doi:10.21037/ tp.2017.03.08.

Real, F., Klein, M., DeBlasio, B., Zackoff, M. W., Yingying, X., Cruse, B., Davis, D. Henize, A., and Beck, A. (2019). CHANGE Asthma: A novel approach to health education through gamification. Pediatrics, 2019;144(2 Meeting Abstract). doi:10.1542/peds.144.2_MeetingAbstract.224.

Roy, M. J., Costanzo, M. R., Highland, K. B., Olsen, C., Clayborne, F., and Law, W. (2017) An app a day keeps the doctor away: Guided education and training via smartphones in subthreshold post-traumatic stress disorder. CyberPsychology, Behavior, and Social Networking, 20(8), 470478. doi:10.1089/cyber.2017.0221.

Sarmiento, K., Thomas, K. E., Daugherty J, Waltzman, D., Haarbauer-Krupa, J. K., Peterson, A. B., Haileyesus, T., and Breiding, M. J. (2019). Emergency department visits for sports- and recreation-related traumatic brain injuries among children - United States, 2010-2016. Morbidity and Mortality Weekly Report, 68, 237-242. doi. org/10.15585/mmwr.mm6810a2.

Teri, S., Acai, A., Griffith, D., Mahmoud, Q., Ma, D. W., and Newton, G. (2014). Student use and pedagogical impact of a mobile learning application. Biochemistry and Molecular Biology Education, 42(2), 121-35. doi: 10.1002/ bmb.20771.

Voelker, R. (2019) Eye-Tracking test approved to help diagnose concussion. JAMA, 321, 7, 638. doi:10.1001/ jama.2019.0509.

Wallace, J., Covassin, T., Nogle, S., Gould, D., and Kovan, J. (2017). Knowledge of concussion and reporting behaviors in high school athletes with or without access to an athletic trainer. Journal of Athletic Training, 52(3), 228-235. doi:10.4085/1062-6050-52.1.07.

Wilson, C. D., Reichsman, F., Mutch-Jones, K., Gardner, A., Marchi, L., Kowalski, S., and Dorsey, C. (2018). Teacher implementation and the impact of game-based science curriculum materials. Journal of Science Education and Technology, 27(4), 285-305. doi: 10.1007/s10956-0179724-y.

Worthen-Chaudhari, L., McGonigal, J., Logan, K., Bockbrader, M. A., Yeates, K. O., and Mysiw, W. J. (2017). Reducing concussion symptoms among teenage youth: Evaluation of a mobile health app. Brain Injury, 31(10), 1279-1286. doi:10.1080/02699052.2017.1332388.

Zahid, A. B., Hubbard, M. E., Lockyer, J., Podolak, O., Dammavalam V. M., Grady, M., Nance, M., Scheiman, M., Samadani, U., and Master, C. L. (2018). Eye tracking as a biomarker for concussion in children. Clinical Journal of Sport Medicine, 2018;00:1-11. doi:10.1097/ JSM.0000000000000639. 